\title{
Fabrication and Photocatalytic Property of One-Dimensional $\mathrm{SrTiO}_{3} / \mathrm{TiO}_{2-x} \mathbf{N}_{x}$ Nanostructures
}

\author{
Huarong Zhang, Miao Guashuai, Ma Xingping, and Wang Bei \\ Institute of Microsystemic Physics and School of Physics \& Electronics, Henan University, Kaifeng 475001, China \\ Correspondence should be addressed to Huarong Zhang; zhanghake@yahoo.com
}

Received 31 January 2013; Revised 18 April 2013; Accepted 19 April 2013

Academic Editor: Gang Liu

Copyright (C) 2013 Huarong Zhang et al. This is an open access article distributed under the Creative Commons Attribution License, which permits unrestricted use, distribution, and reproduction in any medium, provided the original work is properly cited.

One-dimensional $\mathrm{SrTiO}_{3} / \mathrm{TiO}_{2-x} \mathrm{~N}_{x}$ nanostructures were prepared by the hydrothermal method and investigated by $\mathrm{X}$-ray diffraction (XRD), transmission electron microscopy (TEM), X-ray photoelectron spectroscopy (XPS), and ultraviolet-visible diffuse reflectance spectroscopy (UV-vis DRS) measurements. The photocatalytic activities of the prepared samples were evaluated by photodegrading the methylene blue (MB) solution. According to the characterizations, the intermediate product of $\mathrm{SrTiO}_{3}$ /titanate nanotubes was presented after hydrothermal processing of the $\mathrm{TiO}_{2-x} \mathrm{~N}_{x}$ nanoparticles with the mixed solution of $\mathrm{NaOH}$ and $\mathrm{Sr}\left(\mathrm{NO}_{3}\right)_{2}$. The final product of $\mathrm{SrTiO}_{3} / \mathrm{TiO}_{2-x} \mathrm{~N}_{x}$ nanorods was obtained after calcining the intermediate. As compared to the $\mathrm{TiO}_{2-x} \mathrm{~N}_{x}$ nanoparticles, the absorption performance of $\mathrm{SrTiO}_{3} /$ titanate nanotubes or $\mathrm{SrTiO}_{3} / \mathrm{TiO}_{2-x} \mathrm{~N}_{x}$ nanorods was depressed, instead of improving it. The mechanisms of the absorption property changes were discussed. The $\mathrm{SrTiO}_{3} / \mathrm{TiO}{ }_{2-x} \mathrm{~N}_{x}$ nanorods presented better photocatalytic activity than the $\mathrm{TiO}_{2-x} \mathrm{~N}_{x}$ nanoparticles or nanorods. However, due to overmuch adsorption, the $\mathrm{SrTiO}_{3} /$ titanate nanotubes gave ordinary photocatalytic performances.

\section{Introduction}

$\mathrm{TiO}_{2}$ has been extensively investigated for several decades in photocatalysis and photovoltaic areas. Anatase-type $\mathrm{TiO}_{2}$ has attracted great interest as one of the most promising photocatalysts due to its impressed advantages such as high degradation capability, chemical stability, and low cost. However, the application potential of $\mathrm{TiO}_{2}$ photocatalyst is restricted for its low quantum efficiency which is mainly caused by its low light absorption efficiency and high photogenerated charge carrier recombination rate. One-dimensional (1D) nanostructures can facilitate transport of charge carriers and minimize the loss of charge carriers at grain boundaries [1-3]. Hence, the charge carrier recombination of $\mathrm{TiO}_{2}$ is expected to be held back by fabricating 1D nanostructure. Another efficient method to increase the charge separation efficiency of $\mathrm{TiO}_{2}$ is modifying the photocatalyst with some other semiconductors because of the charge carrier transfer between valence or conduction band of two different semiconductors [4-6].

Recently, $\mathrm{TiO}_{2}$ photocatalyst was reported to be modified by various materials such as graphene [7], $\mathrm{Fe}_{3} \mathrm{O}_{4}$ [8], $\mathrm{C}_{60}$
[9], CdS, and $\mathrm{Bi}_{2} \mathrm{~S}_{3}$ [10], by which the photocatalytic activity of $\mathrm{TiO}_{2}$ was enhanced. Moreover, to further improve the photogenerated charge carrier seperation rate, some semiconductors were coupled with prepared $1 \mathrm{D}$ nanostructures (such as nanotube, nanofiber, and nanorod). Zhai et al. reported high photoactivities in the visible light responsive graphene/titanate nanotubes photocatalysts fabricated by hydrothermal method [11]. Yi et al. fabricated the silver nanoparticles, decorated nanobranched $\mathrm{TiO}_{2}$ nanofibers, and presented that the photocatalytic degradation rates of silver loaded on nanobranched $\mathrm{TiO}_{2}$ nanofibers were 1.6 and 1.7 times as those of pure $\mathrm{TiO}_{2}$ nanofibers in the presence of methylene blue and methyl orange, respectively [12].

Cubic-perovskite-type $\mathrm{SrTiO}_{3}$, a multimetallic oxide semiconductor with a band gap of $3.4 \mathrm{eV}$ comparable to $\mathrm{TiO}_{2}$, has drawn considerable interest because of its applications in storage batteries, thermoelectric property, solar cell, and photocatalysis [13-16]. $\mathrm{SrTiO}_{3}$ is a good candidate for coupling $\mathrm{TiO}_{2}$ and improving the photocatalytic performance of the photocatalyst because its conduction band edge is more negative than $\mathrm{TiO}_{2}$. Due to the potential differences between 
the band edges of these two semiconductors, the photogenerated electrons transfer from the conduction band of $\mathrm{SrTiO}_{3}$ to that of $\mathrm{TiO}_{2}$. Conversely, the photogenerated electrons transfer from the conduction band of $\mathrm{SrTiO}_{3}$ to that of $\mathrm{TiO}_{2}$. Then the photogenerated charge carriers can be efficiently separated by these processes, resulting in the enhancement of the photocatalytic property in the photocatalyst. Recently, some research work about $\mathrm{SrTiO}_{3} / \mathrm{TiO}_{2}$ photocatalysts has been reported [17-19]. On the other hand, it has been extensively reported that $\mathrm{N}$-doping could obviously improve the photocatalytic activity of $\mathrm{TiO}_{2}[20,21]$. In this work, we fabricated one-dimensional $\mathrm{SrTiO}_{3} / \mathrm{TiO}_{2-x} \mathrm{~N}_{x}$ nanostructures by the hydrothermal method. The photocatalyic activity for the degradation of methylene blue $(\mathrm{MB})$ solution in the Ndoped $\mathrm{TiO}_{2}$ was greatly enhanced after coupling with $\mathrm{SrTiO}_{3}$.

\section{Materials and Methods}

2.1. Sample Preparation. Anatase nanocrystalline $\mathrm{TiO}_{2-x} \mathrm{~N}_{x}$ was synthesized by a simple sol-gel method as our previous work described [22]. Different amounts of $\mathrm{Sr}\left(\mathrm{NO}_{3}\right)_{2}$ were dissolved in $40 \mathrm{~mL}$ of $10 \mathrm{~mol} / \mathrm{L} \mathrm{NaOH}$ solution. Then $0.78 \mathrm{~g}$ $\mathrm{N}-\mathrm{TiO}_{2}$ powder was dispersed into the mixture solution to form a suspension which was heated at $180^{\circ} \mathrm{C}$ for $24 \mathrm{~h}$ under hydrothermal condition in a PTFE-lined stainless steel vessel. The observed sediment at the bottom of the vessel was washed with $0.1 \mathrm{~mol} / \mathrm{L} \mathrm{HCl}$ solutions until $\mathrm{pH}$ is less than 7 , followed by washing with DI water and drying at $80^{\circ} \mathrm{C}$ in air overnight. The dried powder was milled and calcined at $400^{\circ} \mathrm{C}$ under air for $2 \mathrm{~h}$. $\mathrm{SrTiO}_{3} / \mathrm{N}-\mathrm{TiO}_{2}$ samples with different ratios of $\mathrm{SrTiO}_{3}$ were then prepared.

2.2. Characterization and Measurements. X-ray diffraction (XRD) patterns were recorded on a DX-2500 diffractometer (Fangyuan, Dandong) with $\mathrm{Cu} \mathrm{K} \alpha$ radiation with $\lambda=$ $0.154145 \mathrm{~nm}$. Transmission electron microscopy (TEM) measurements were carried out on a JEOL-2010 TEM at an acceleration voltage of $200 \mathrm{kV}$. X-ray photoelectron spectroscopy (XPS) measurements were recorded on an Axis Ultra system with monochromatic $\mathrm{Al} \mathrm{K} \alpha \mathrm{X}$-rays (1486.6 ev) operated at $45 \mathrm{~W}$ and $15 \mathrm{kV}$ with a background pressure of approximately $5.0 \times 10^{-9}$ Torr. A survey spot size and $40 \mathrm{eV}$ pass energy were used for the analysis. Emitted photoelectrons perpendicular to the sample surface were collected. The binding energy of all investigated elements was referenced by the $\mathrm{C} 1 \mathrm{~s}$ peak at $284.8 \mathrm{eV}$ of the surface adventitious carbon, respectively. The diffuse reflection spectra were obtained on an UV-vis spectrophotometer (Varian Cary 5000) using $\mathrm{BaSO}_{4}$ as the reference standard and were converted to the absorbance data through the Kubelka-Munk method.

Photocatalytic experiments were carried out in an innerirradiation-type reactor. A cylindrical reaction cell was used to contain the reaction solution, and a $500 \mathrm{~W}$ long-arc xenon lamp surrounded with a water cooling system was fixed in the center of the reaction cell. $30 \mathrm{mg}$ of photocatalyst was suspended in $200 \mathrm{~mL}$ of a methylene blue (MB) solution $(10 \mathrm{mg} / \mathrm{L})$ under stirring magnetically. The mixture was kept in the dark for 30 minutes to establish an

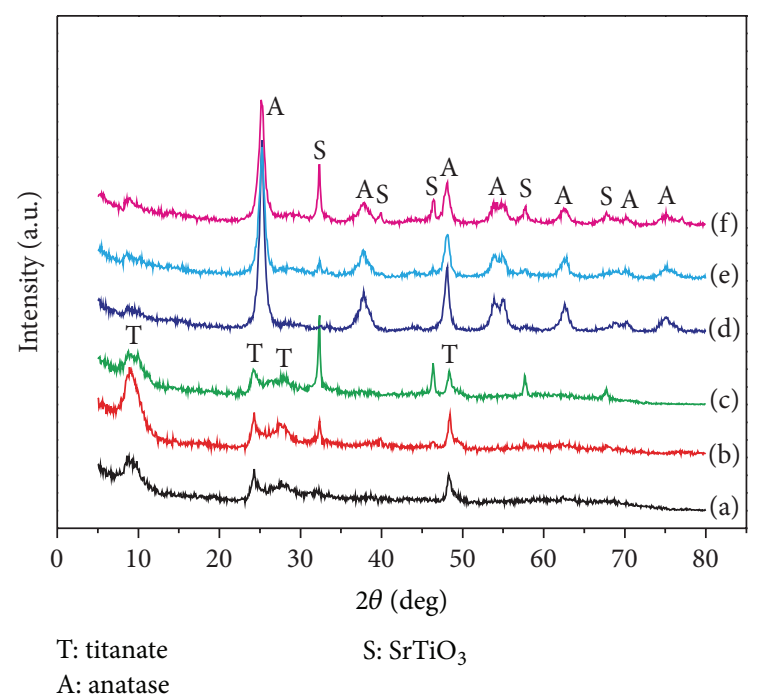

FIGURE 1: XRD patterns for the uncalcined ((a): $1 \%$; (b): $2 \%$; (c): $5 \%)$ and calcined ((d): $1 \%$; (e): $2 \%$; (f): $5 \%)$ samples with different $\mathrm{Sr} / \mathrm{Ti}$ ratios.

adsorption-desorption equilibrium before the light radiation. The amount of $\mathrm{MB}$ in the solution was determined on the basis of its characteristic optical absorption at $665 \mathrm{~nm}$ using a visible light spectrophotometer (Model: 723C) based on Lambert-Beer's law.

\section{Results and Discussion}

3.1. Crystal Structure and Morphology. The XRD patterns of the uncalcined and calcined samples are presented in Figure 1 . The main diffraction peaks at about $9.1^{\circ}, 24.3^{\circ}, 28.0^{\circ}$, and $48.3^{\circ}$ in the patterns of the uncalcined samples (Figures $1(\mathrm{a}), 1(\mathrm{~b})$, and $1(\mathrm{c})$ ) are designated to the protonic titanate phase [23]. Additionally, with the increase of the Sr/Ti ratio, the intensity of the diffraction peaks contributed by $\mathrm{SrTiO}_{3}$ at about $32.3^{\circ}, 46.4^{\circ}, 57.5^{\circ}$, and $67.6^{\circ}$ gradually increases. From Figures 1(d), 1(e), and 1(f), it can be found that main crystalline phases in the calcined samples involve the anatase and $\mathrm{SrTiO}_{3}$ phase. Figure 2 shows the morphologies of the uncalcined and calcined samples. From the TEM results as shown in Figures 2(a), 2(b), and 2(c), it is found that the uncalcined samples are all composed of nanotubes with lengths about 200-300 $\mathrm{nm}$ and diameters about $10 \mathrm{~nm}$. After the calcination, the nanotubes in the uncalcined samples morph into nanorods with diameters of $510 \mathrm{~nm}$ and different lengths as Figures 2(d), 2(e), and 2(f) show.

3.2. XPS Measurements. Figure 3 shows the XPS spectra of $\mathrm{O}$ $1 s, \mathrm{~N} 1 s$, Ti $2 p$, and $\mathrm{Sr} 3 d$ for the $\mathrm{SrTiO}_{3} / \mathrm{TiO}_{2-x} \mathrm{~N}_{x}$ with the $\mathrm{Sr} / \mathrm{Ti}$ ratio of $5 \%$. After fitting the result of O $1 s$ XPS, it can be found that two peaks centered at $529.8 \mathrm{eV}$ and 531.2 are observed in the O $1 \mathrm{~s}$ XPS peak, attributing to bulk oxygen bonded to titanium and surface hydroxyl oxygen in $\mathrm{TiO}_{2}$, respectively [22, 24]. From Figure 3, a similar broad peak from $397 \mathrm{eV}$ to $403 \mathrm{eV}$ is displayed in the XPS pattern of $\mathrm{N}$ 


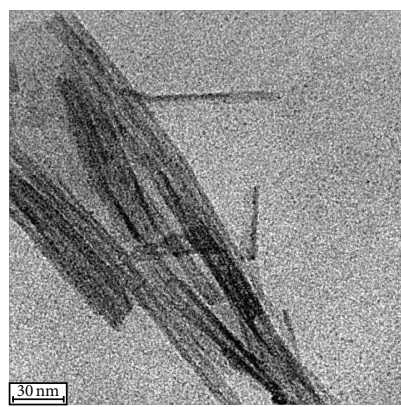

(a)

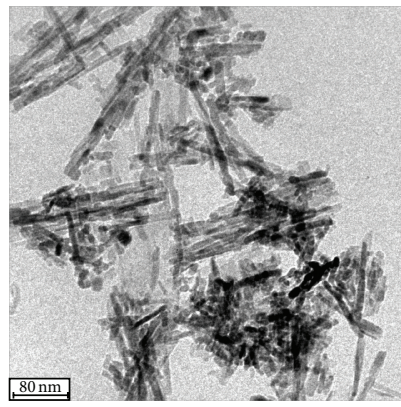

(d)

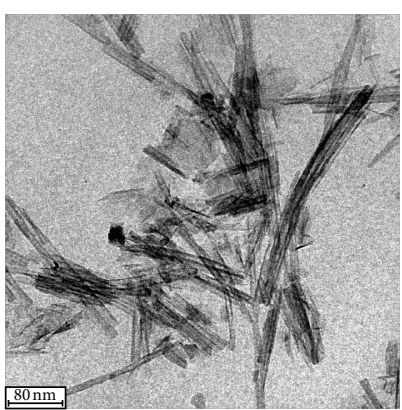

(b)

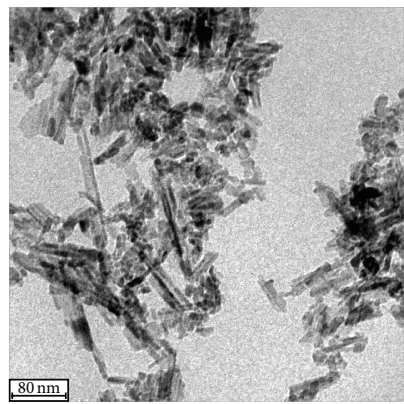

(e)

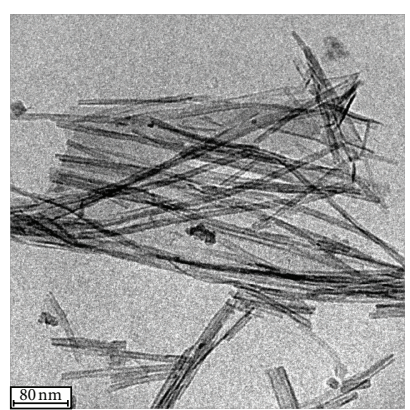

(c)

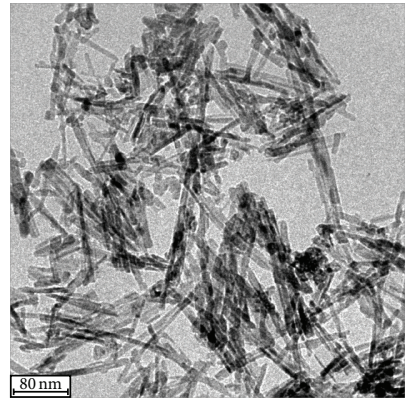

(f)

Figure 2: TEM images of the uncalcined ((a): 1\%; (b): 2\%; (c): 5\%) and calcined ((d): 1\%; (e): 2\%; (f): 5\%) samples with different Sr/Ti ratios.

1s state with our previous work where the broad $\mathrm{N} 1 s$ peak in the XPS pattern of the $(\mathrm{Y}, \mathrm{N})$-codoped $\mathrm{TiO}_{2}$ was attributed to the formation of the $\mathrm{O}-\mathrm{Ti}-\mathrm{N}$ (substitutional $\mathrm{N}$ ) and $\mathrm{Ti}-$ $\mathrm{O}-\mathrm{N}$ (interstitial $\mathrm{N}$ ) structures in the lattice of $\mathrm{TiO}_{2}$ during the nitridation process [22]. The XPS result of $\mathrm{N} 1 s$ also indicates that $\mathrm{N}$ still exists in the lattice of $\mathrm{TiO}_{2}$ after the hydrothermal process. As shown in Figure 3, two peaks at 458.6 and $464.6 \mathrm{eV}$ are observed in the spectrum of Ti $2 p$, which corresponds to the $2 p_{3 / 2}$ and $\mathrm{Ti} 2 p_{1 / 2}$ states of $\mathrm{Ti}^{4+}$, respectively [22]. By fitting the XPS result of Sr $3 d$, two peaks at about 133.0 and $134.7 \mathrm{eV}$ are revealed, assigning to the $\mathrm{Sr}$ $3 d$ electronic states in the $\mathrm{SrTiO}_{3}$ perovskite material and $\mathrm{SrO}$ complexes, respectively [24-26].

3.3. UV-Vis Spectroscopy. Figure 4 shows the UV-vis spectra of the uncalcined and calcined samples. It can be observed that all the absorption spectra in Figure 4 exhibit typical absorption behavior of the wide band gap oxide semiconductor, having an intense absorption band with a steep edge. From the spectra, the absorption edges of the uncalcined $\left(\mathrm{SrTiO}_{3} /\right.$ titanate) samples with the $\mathrm{Sr} / \mathrm{Ti}$ ratio of $0 \%, 1 \%, 2 \%$, and 5\%, respectively, lie at 390.9, 392.5, 408.4, and $396.7 \mathrm{~nm}$ as shown in Figure 4 (curves (a)-(d)). The absorption edges of the calcined $\left(\mathrm{SrTiO}_{3} / \mathrm{TiO}_{2-x} \mathrm{~N}_{x}\right)$ samples with the $\mathrm{Sr} / \mathrm{Ti}$ ratio of $0 \%, 1 \%, 2 \%$, and $5 \%$, respectively, lie at $424.5,408.9,418.8$, and $402.1 \mathrm{~nm}$ (see curves (e)-(h) in Figure 4). Compared with the absorption edges of uncalcined samples, the absorption edges of the calcined samples shift slightly toward lower energy, respectively, which can be attributed to the differences of band structure and morphologies between titanate nanotubes and anatase nanorods. On the other hand, slight

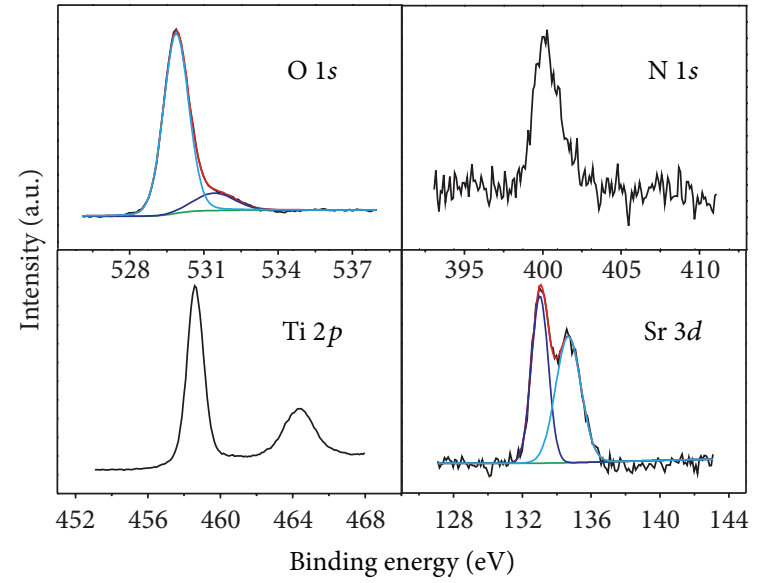

Figure 3: XPS spectra of O $1 s, \mathrm{~N} 1 s, \mathrm{Ti} 2 p$, and $\mathrm{Sr} 3 d$ for the $\mathrm{SrTiO}_{3} / \mathrm{TiO}_{2-x} \mathrm{~N}_{x}$ with the $\mathrm{Sr} / \mathrm{Ti}$ ratio of $5 \%$.

red shifts can be observed in the $\mathrm{SrTiO}_{3} /$ titanate samples after decorating titanate with $\mathrm{SrTiO}_{3}$. However, different absorption edge blue shifts occur in the $\mathrm{SrTiO}_{3} / \mathrm{TiO}_{2-x} \mathrm{~N}_{x}$ samples as compared to the undecorated $\mathrm{TiO}_{2-x} \mathrm{~N}_{x}$. The origins of absorption edge shifts after the decoration of $\mathrm{SrTiO}_{3}$ are still under discussion. It is known that the Ndoping in $\mathrm{TiO}_{2}$ nanoparticles can result in obvious visible photocatalytic activity because the band narrowing and oxygen vacancies caused by the $\mathrm{N}$-doping can greatly extend the optical absorption range to visible light region. The inset of Figure 4 shows the absorption spectrum of the $\mathrm{TiO}_{2-x} \mathrm{~N}_{x}$ 


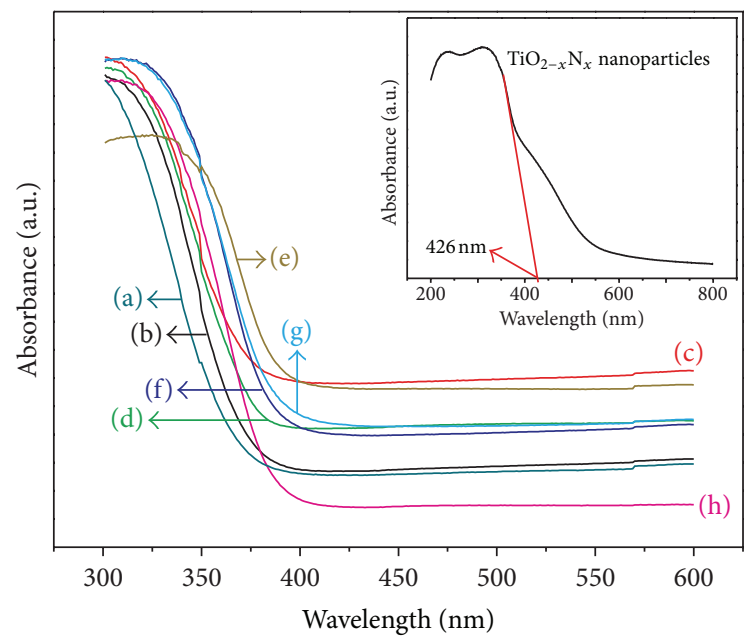

FIGURE 4: UV-vis absorption spectra of the uncalcined ((a): 0\%; (b): 1\%; (c): $2 \%$; (d): $5 \%$ ) and calcined ((e): $0 \%$; (f): $1 \%$; (g): $2 \%$; (h): $5 \%)$ samples with different $\mathrm{Sr} / \mathrm{Ti}$ ratios.

nanoparticles which reveals that the absorption edge lies at $426.0 \mathrm{~nm}$, and a broad absorption shoulder is observed from 380 to $550 \mathrm{~nm}$. According to the calculational results by Dong et al. [27], the highest localized state for the substitutional $\mathrm{N}$ state is $0.14 \mathrm{eV}$ above the top of the valence band and $0.73 \mathrm{eV}$ for the interstitial $\mathrm{N}$ state. $\mathrm{N}$-doping simultaneously favored the formation of oxygen vacancy whose electronic states are located $0.8 \mathrm{eV}$ below the conduction band minimum. Herein, in our opinion, the absorption edge at $426.0 \mathrm{~nm}$ can be attributed to the electron transition from the substitutional $\mathrm{N}$ states to the conduction band, and the absorption shoulder is contributed by the electron transition between the valence (or conduction) band and the oxygen vacancy (or interstitial N) states. It should be noted that the absorption shoulder is not presented in the spectra of the uncalcined or calcined samples, indicating the decrease or vanishing of oxygen vacancies and interstitial $\mathrm{N}$ after the hydrothermal process.

3.4. Photocatalytic Activity. The photocatalytic activities of the prepared samples were evaluated by monitoring the degradation of $\mathrm{MB}$ solution, where the concentration of $\mathrm{MB}$ was obtained from the linear relation between the absorbance and the concentration of MB solution. Figure 5 displays the degradation rate of $\mathrm{MB}$ as a function of light irradiation time without any photocatalyst (the blank test) and over the photocatalysts of $\mathrm{TiO}_{2-x} \mathrm{~N}_{x}$ nanoparticles, $\mathrm{TiO}_{2-x} \mathrm{~N}_{x}$ nanorods, and $\mathrm{SrTiO}_{3} / \mathrm{TiO}_{2-x} \mathrm{~N}_{x}$ nanorods with different amounts of $\mathrm{SrTiO}_{3}$ and $\mathrm{SrTiO}_{3} /$ titanate nanotube with $5 \% \mathrm{Sr} / \mathrm{Ti}$ ratio. Firstly, the $\mathrm{TiO}_{2-x} \mathrm{~N}_{x}$ nanorods sample presents a similar photocatalytic performance with the sample of $\mathrm{TiO}_{2-x} \mathrm{~N}_{x}$ nanoparticles even though the photoabsorption efficiency of the former is obviously lower than that of the latter. According to the $\mathrm{C} / \mathrm{C}_{0}$ values of these two samples after 30 of minutes dark reaction, the adsorption capability of the $\mathrm{TiO}_{2-x} \mathrm{~N}_{x}$

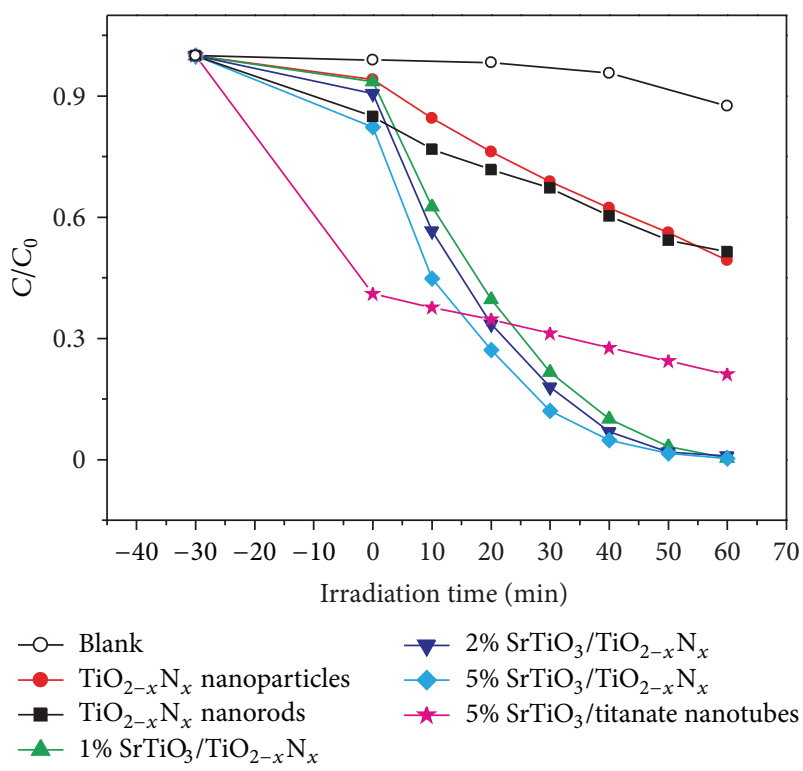

FIGURE 5: Photodegradation of MB under light irradiation without any photocatalyst (blank) and over the prepared photocatalysts.

nanorods is better than that of the nanoparticles. Moreover, as described above, the charge carrier recombination of $\mathrm{TiO}_{2}$ is expected to be held back by fabricating $1 \mathrm{D}$ nanostructure. The above two factors are both positive to the photocatalytic activity of $\mathrm{TiO}_{2-x} \mathrm{~N}_{x}$ nanorods. Secondly, the photocatalytic property of $\mathrm{TiO}_{2-x} \mathrm{~N}_{x}$ nanorods was greatly enhanced after the decoration of $\mathrm{SrTiO}_{3}$ as shown in Figure 5. With the increase of the amount of $\mathrm{SrTiO}_{3}$, the photocatalytic properties of the $\mathrm{SrTiO}_{3} / \mathrm{TiO}_{2-x} \mathrm{~N}_{x}$ samples are improved gradually. Here, the visible light photodegradation experiments using a light source with a UV cut were also performed which revealed that there was almost no visible light photocatalytic activity in the samples of $\mathrm{SrTiO}_{3} / \mathrm{TiO}_{2-x} \mathrm{~N}_{x}$. This result is expected; after all, the decoration of $\mathrm{SrTiO}_{3}$ cannot enhance the visible light absorption in the $\mathrm{TiO}_{2-x} \mathrm{~N}_{x}$ photocatalyst. As described above, $\mathrm{SrTiO}_{3}$ is a good candidate for coupling $\mathrm{TiO}_{2}$ to improve the photocatalytic performance of the photocatalyst because the photogenerated charge carriers can be efficiently separated after the modification of $\mathrm{SrTiO}_{3}$. As a result, better photocatalytic properties were presented in the composite samples than the sample of $\mathrm{TiO}_{2-x} \mathrm{~N}_{x}$. Lastly, as Figure 5 shows, the photocatalytic activity of the $\mathrm{SrTiO}_{3} /$ titanate nanotubes is obviously inferior to the other samples even though its adsorption capability is best among all the samples. From the $\mathrm{C} / \mathrm{C}_{0}$ values of all the samples after the dark reaction, the adsorption capability of the nanotubes is obviously more prominent than the other samples. Generally, the better adsorption capability will indicate a better photocatalytic performance in a type of photocatalyst. However, overmuch adsorbed degrading dye will cover the photocatalytic active sites existing on the photocatalyst surface which is detrimental to the photocatalytic activity of photocatalyst. Herein, in our opinion, overmuch adsorption on the nanotubes surface causes the decrease of photocatalytic property in the $\mathrm{SrTiO}_{3} /$ titanate sample. 


\section{Conclusions}

In summary, $\mathrm{SrTiO}_{3} / \mathrm{TiO}_{2-x} \mathrm{~N}_{x}$ nanostructures were fabricated by the hydrothermal method and characterized by XRD, TEM, XPS, and UV-vis DRS measurements. After hydrothermal processing of the $\mathrm{TiO}_{2-x} \mathrm{~N}_{x}$ nanoparticles with the mixed solution of $\mathrm{NaOH}$ and $\mathrm{Sr}\left(\mathrm{NO}_{3}\right)_{2}, \mathrm{SrTiO}_{3} /$ titanate nanotubes were obtained and presented ordinary photocatalytic performances even though their adsorption properties were greatly improved, indicating that overmuch adsorption is detrimental to the photocatalytic activity of photocatalysts. After calcining the $\mathrm{SrTiO}_{3} /$ titanate nanotubes, $\mathrm{SrTiO}_{3} / \mathrm{TiO}_{2-x} \mathrm{~N}_{x}$ nanorods were produced and showed greatly enhanced photocatalytic activities even though their optical absorption performances were depressed as compared to the $\mathrm{TiO}_{2-x} \mathrm{~N}_{x}$. The mechanisms about the absorption and photocatalytic properties in the prepared samples were discussed in detail.

\section{Acknowledgments}

This work is financially supported by the Scientific and Technological Research Project of Henan Province (Grant no. 122102210229) and the Research Project of Province-ministry Coconstructing Henan University (SBGJ090505).

\section{References}

[1] J. Zhang, J. H. Bang, C. C. Tang, and P. V. Kamat, "Tailored $\mathrm{TiO}_{2}-\mathrm{SrTiO}_{3}$ heterostructure nanotube arrays for improved photoelectrochemical performance," ACS Nano, vol. 4, no. 1, pp. 387-395, 2010.

[2] A. Kongkanand, K. Tvrdy, K. Takechi, M. K. Kuno, and P. V. Kamat, "Quantum dot solar cells. Tuning photoresponse through size and shape control of $\mathrm{CdSe}-\mathrm{TiO}_{2}$ architecture," Journal of the American Chemical Society, vol. 130, no. 12, pp. 4007-4015, 2008.

[3] Q. Wang, K. Zhu, N. R. Neale, and A. J. Frank, "Constructing ordered sensitized heterojunctions: bottom-up electrochemical synthesis of p-type semiconductors in oriented $\mathrm{n}-\mathrm{TiO}_{2}$ nanotube arrays," Nano Letters, vol. 9, no. 2, pp. 806-813, 2009.

[4] T. Tsumura, K. Sogabe, and M. Toyoda, "Preparation of $\mathrm{SrTiO}_{3}$ supported $\mathrm{TiO}_{2}$ photocatalyst," Materials Science and Engineering $B$, vol. 157, no. 1-3, pp. 113-115, 2009.

[5] B. Zielinska and A. W. Morawski, " $\mathrm{TiO}_{2}$ photocatalysts promoted by alkali metals," Applied Catalysis B, vol. 55, no. 3, pp. 221-226, 2005.

[6] H. L. Meng, C. Cui, H. L. Shen et al., "Synthesis and photocatalytic activity of $\mathrm{TiO}_{2} @ \mathrm{CdS}$ and CdS@TiO 2 double-shelled hollow spheres," Journal of Alloys and Compounds, vol. 527, pp. 30-35, 2012.

[7] P. N. Zhu, A. S. Nair, S. J. Peng, S. Y. Yang, and S. Ramakrishna, "Facile fabrication of $\mathrm{TiO}_{2}$-graphene composite with enhanced photovoltaic and photocatalytic properties by electrospinning," ACS Applied Materials \& Interfaces, vol. 4, no. 2, pp. 581-585, 2012.

[8] M. S. Islam, Y. Kusumoto, M. Abdulla-Al-Mamun, and Y. Horie, "Photocatalytic and AC magnetic-field induced enhanced cytotoxicity of $\mathrm{Fe}_{3} \mathrm{O}_{4}-\mathrm{TiO}_{2}$ core-shell nanocomposites against HeLa cells," Catalysis Communications, vol. 16, no. 1, pp. 39-44, 2011.
[9] Z. D. Meng, M. M. Peng, L. Zhu, W. C. Oh, and F. J. Zhang, "Fullerene modification $\mathrm{CdS} / \mathrm{TiO}_{2}$ to enhancement surface area and modification of photocatalytic activity under visible light," Applied Catalysis B, vol. 113-114, pp. 141-149, 2012.

[10] Y. Bessekhouad, D. Robert, and J. V. Weber, " $\mathrm{Bi}_{2} \mathrm{~S}_{3} / \mathrm{TiO}_{2}$ and $\mathrm{CdS} / \mathrm{TiO}_{2}$ heterojunctions as an available configuration for photocatalytic degradation of organic pollutant," Journal of Photochemistry and Photobiology A, vol. 163, no. 3, pp. 569-580, 2004.

[11] Q. Q. Zhai, T. Bo, and G. X. Hu, "High photoactive and visiblelight responsive graphene/titanate nanotubes photocatalysts: preparation and characterization," Journal of Hazardous Materials, vol. 198, pp. 78-86, 2011.

[12] C. Yi, R. Nirmala, N. A. M. Barakat, R. Navamathavan, and H. Y. Kim, "Photocatalytic properties of silver nanoparticles decorated nanobranched $\mathrm{TiO}_{2}$ nanofibers," Journal of Nanoscience and Nanotechnology, vol. 11, no. 8, pp. 6886-6892, 2011.

[13] N. Iwata, K. Yamaguchi, T. B. Nishimura, K. Takemura, and Y. Miyasaka, "Li-ion battery operated power amplifier MMICs utilizing $\mathrm{SrTiO}_{3}$ capacitors and heterojunction FETs for PDC and CDMA cellular phones," Solid-State Electronics, vol. 43, no. 4, pp. 747-753, 1999.

[14] Y. J. Cui, J. He, G. Amow, and H. Kleinke, "Thermoelectric properties of $n$-type double substituted $\mathrm{SrTiO}_{3}$ bulk materials," Dalton Transactions, vol. 39, no. 4, pp. 1031-1035, 2010.

[15] I. Hod, M. Shalom, Z. Tachan, S. Rühle, and A. Zaban, " $\mathrm{SrTiO}_{3}$ recombination-inhibiting barrier layer for type II dyesensitized solar cells," Journal of Physical Chemistry C, vol. 114, no. 21, pp. 10015-10018, 2010.

[16] U. Sulaeman, S. Yin, and T. Sato, "Visible light photocatalytic activity induced by the carboxyl group chemically bonded on the surface of $\mathrm{SrTiO}_{3}$," Applied Catalysis B, vol. 102, no. 1-2, pp. 286-290, 2011.

[17] T. P. Cao, Y. J. Li, C. H. Wang, C. L. Shao, and Y. C. Liu, "A facile in situ hydrothermal method to $\mathrm{SrTiO}_{3} / \mathrm{TiO}_{2}$ nanofiber heterostructures with high photocatalytic activity," Langmuir, vol. 27, no. 6, pp. 2946-2952, 2011.

[18] J. Zhang, J. H. Bang, C. Tang, and P. V. Kamat, "Tailored $\mathrm{TiO}_{2}-\mathrm{SrTiO}_{3}$ heterostructure nanotube arrays for improved photoelectrochemical performance," ACS Nano, vol. 4, no. 1, pp. 387-395, 2010.

[19] J. H. Yan, Y. R. Zhu, Y. G. Tang, and S. Q. Zheng, "Nitrogendoped $\mathrm{SrTiO}_{3} / \mathrm{TiO}_{2}$ composite photocatalysts for hydrogen production under visible light irradiation," Journal of Alloys and Compounds, vol. 472, no. 1-2, pp. 429-433, 2009.

[20] R. Asahi, T. Morikawa, T. Ohwaki, K. Aoki, and Y. Taga, "Visible-light photocatalysis in nitrogen-doped titanium oxides," Science, vol. 293, no. 5528, pp. 269-271, 2001.

[21] Z. H. Zhao, J. M. Fan, J. Y. Wang, and R. F. Li, "Effect of heating temperature on photocatalytic reduction of $\mathrm{CO}_{2}$ by $\mathrm{N}-\mathrm{TiO}_{2}$ nanotube catalyst," Catalysis Communications, vol. 21, pp. 3237, 2012.

[22] H. R. Zhang, K. Q. Tan, H. W. Zheng, Y. Z. Gu, and W. F. Zhang, "Preparation, characterization and photocatalytic activity of $\mathrm{TiO}_{2}$ codoped with yttrium and nitrogen," Materials Chemistry and Physics, vol. 125, no. 1-2, pp. 156-160, 2011.

[23] X. B. Chen, H. Q. Wang, S. Gao, and Z. B. Wu, "Effect of pH value on the microstructure and $\operatorname{deNO}_{x}$ catalytic performance of titanate nanotubes loaded $\mathrm{CeO}_{2}$," Journal of Colloid and Interface Science, vol. 377, no. 1, pp. 131-136, 2012.

[24] J. W. Ng, S. P. Xu, X. W. Zhang, H. Y. Yang, and D. D. Sun, "Hybridized nanowires and cubes: a novel architecture of 
a heterojunctioned $\mathrm{TiO}_{2} / \mathrm{SrTiO}_{3}$ thin film for efficient water splitting," Advanced Functional Materials, vol. 20, no. 24, pp. 4287-4294, 2010.

[25] W. D. Yang, "X-ray photoelectron spectroscopy and electrical properties studies of $\mathrm{La}_{2} \mathrm{O}_{3}$-doped strontium titanate ceramics prepared by sol-precipitation method," Journal of Materials Science, vol. 34, no. 14, pp. 3533-3544, 1999.

[26] R. P. Vasquez, "X-ray photoelectron spectroscopy study of $\mathrm{Sr}$ and Ba compounds," Journal of Electron Spectroscopy and Related Phenomena, vol. 56, no. 3, pp. 217-240, 1991.

[27] F. Dong, W. R. Zhao, Z. B. Wu, and S. Guo, "Band structure and visible light photocatalytic activity of multi-type nitrogen doped $\mathrm{TiO}_{2}$ nanoparticles prepared by thermal decomposition," Journal of Hazardous Materials, vol. 162, no. 2-3, pp. 763-770, 2009. 

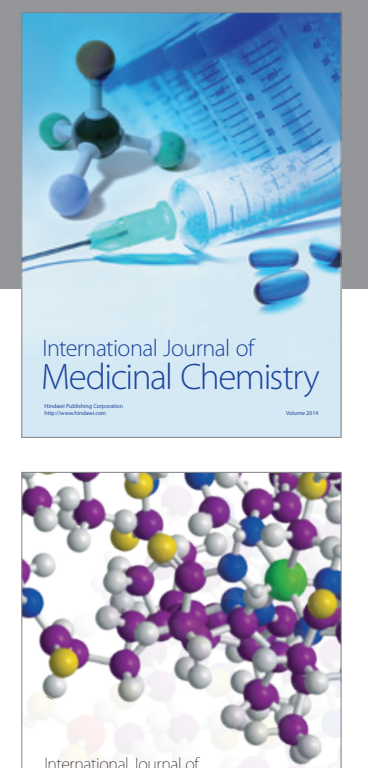

\section{Carbohydrate} Chemistry

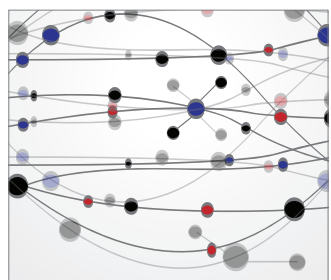

The Scientific World Journal
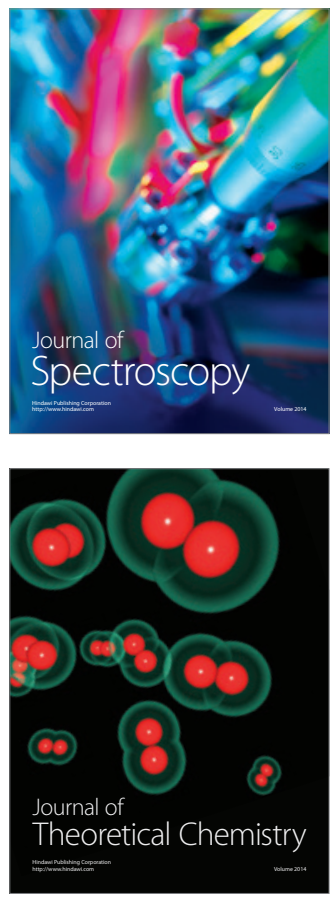
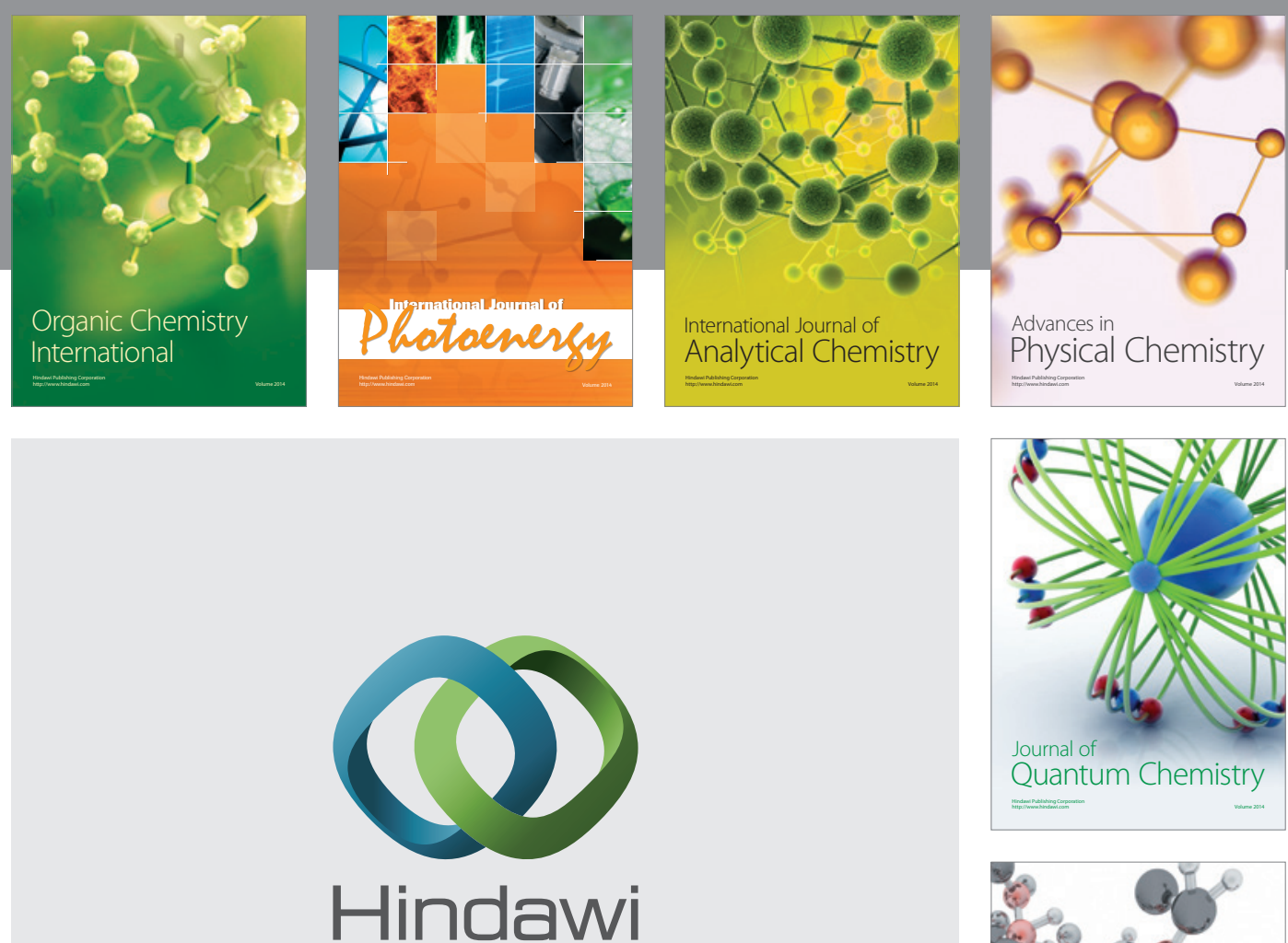

Submit your manuscripts at

http://www.hindawi.com

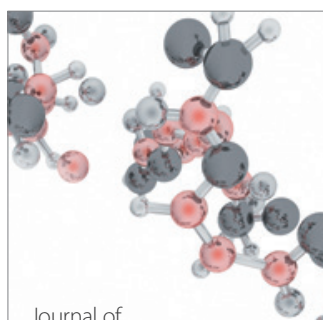

Analytical Methods

in Chemistry

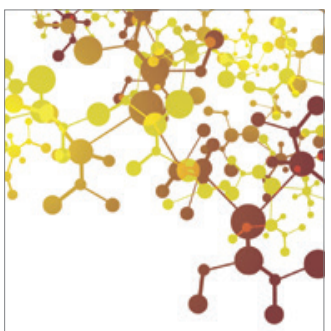

Journal of

Applied Chemistry

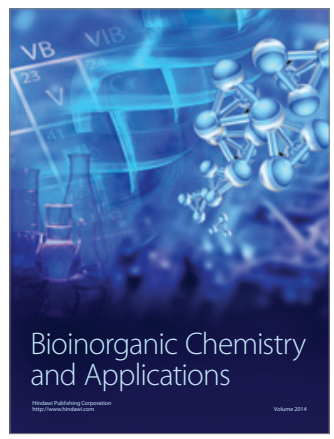

Inorganic Chemistry
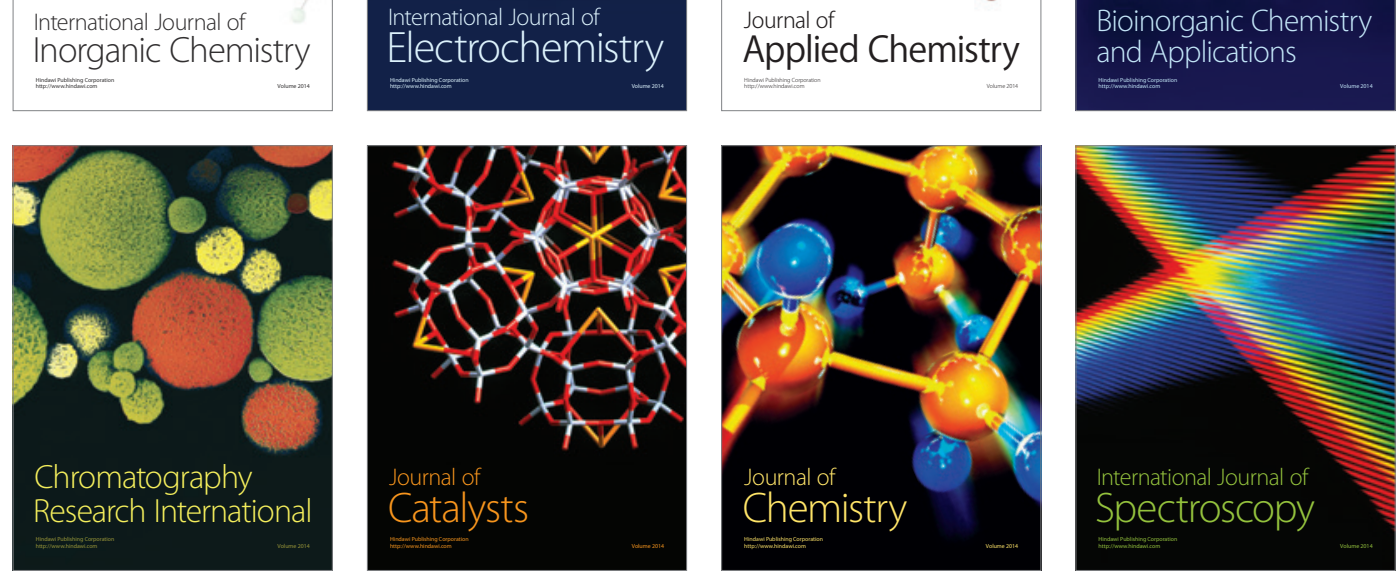